\title{
O CONCÍlIO VATICANO II: APONTAMENTOS BIBLIOGRÁFICOS PARA UM ESTUDO HISTORIOGRÁFICO ${ }^{1}$
}

\author{
The Second Vatican Council: \\ Bibliographical notes for a historiographical study
}

\author{
Rodrigo Coppe Caldeira *
}

RESUMO: Os estudos historiográficos sobre o maior evento do cristianismo no século XX, o Concílio Vaticano II (1962-1965), ainda dão seus primeiros passos no Brasil. Partindo desse pressuposto, este artigo tem como objetivo principal revisitar uma bibliografia fundamental para as realizações deste tipo de estudos, além de apresentar um breve adendo hermenêutico sobre a interpretação do evento conciliar.

Palavras-chave: História da Igreja, Concílio Vaticano II, Historiografia, Hermenêutica.

ABSTRACT: The historiographical studies on the Second Vatican Council (19621965), the biggest event of Christianity in the twentieth century, still take their first steps in Brazil. From that perspective, this paper's main objective is to revisit a basic bibliography for the achievement of such studies, and also present a brief hermeneutic addendum on the interpretation of the councilor event.

KEYwORDS: Church history, Second Vatican Council, Historiography, Hermeneutic.

\footnotetext{
* Departamento de Ciências da Religião da PUC-Minas. Artigo submetido a avaliação no dia 18/12/2010 e aprovado para publicação no dia 20/12/2010.

${ }^{1}$ Este artigo reflete pesquisa de doutorado para o Programa de Pós-graduação em Ciência da Religião da Universidade Federal de Juiz de Fora. No caso, o autor foi contemplado por bolsa de doutorado do CNPq.
} 


\section{Considerações iniciais}

$M$ uito se falou e se falará sobre um dos eventos mais importantes do século XX: o Concílio Vaticano II. Nos próximos anos completam-se cinquenta anos de seu início, e com certeza não faltarão análises e estudos referentes aos seus documentos, seus dramas e desilusões, suas tomadas de posição, seus conflitos. A sua história é complexa e precisaríamos de anos para compreender seus desenvolvimentos internos, suas reviravoltas e a movimentação de seus principais atores. De fato, estamos num momento histórico em que o próprio concílio ainda não foi "recebido" de todo. Estamos ainda numa fase de recepção de suas determinações, e por isso, vivemos conflitos de interpretação sobre os seus significados ${ }^{2}$.

A partir da conclusão de minha tese de doutorado em Ciência das Religiões - Os baluartes da tradição: a antimodernidade católica brasileira no Concílio Vaticano $\mathrm{II}^{3}$-, arrazoei a possibilidade de um artigo que passasse por uma literatura que - penso eu - seja indispensável para quem deseja estudar o concílio a partir de uma perspectiva historiográfica. Dessa maneira, objetivo apontar neste breve artigo as principais obras que me ajudaram a compreender um pouco mais o evento em si, suas diferentes dimensões e abrir caminho em busca das fontes primárias - além de salpicar algumas considerações teóricas particulares no decorrer do texto.

\section{Adendo teórico-hermenêutico da história do Concílio Vaticano II}

A história do Concílio Vaticano II está ainda por se fazer. Como todo processo investigativo comporta em si uma dimensão interpretativa, e toda dimensão interpretativa compreende-se limitada pela contingência, o Vaticano II - mais quando estamos ainda sob influências de grupos que o viveram em carne e osso, vide Joseph Ratzinger - apresenta-se como um evento relativamente recente, que gera debates acalorados em importantes escolas históricas e teológicas do mundo, e que está aberto a novas interpretações. De qualquer maneira, frente a frente a um momento específico,

\footnotetext{
${ }^{2}$ Cf. Discurso do papa Bento XVI para a Cúria Romana no Natal de 2005. Tratei da questão em R.C. CALDEIRA, "Reflexões acerca da continuidade e descontinuidade no Vaticano II: possibilidades de análise", Revista de Cultura Teológica 3 (2008) 1-13; ID., "Bases temporais para o estudo histórico da Igreja católica no século XX", Horizonte 5 (2008) 75-90.

${ }^{3}$ R.C. CALDEIRA, Os baluartes da Tradição: a antimodernidade católica brasileira no Concílio Vaticano II, Tese de doutorado, Programa de Pós-Graduação em Ciência da Religião da Universidade Federal de Juiz de Fora, 2009.
} 
que gera inquietudes e que coloca a Igreja a se perguntar - seja entre os executores diretos da burocracia vaticana, seja entre fiéis leigos, padres e religiosos de todo o planeta onde ela se faz presente -, como vem fazendo há séculos, especialmente depois da chamada "emergência da modernidade" (o que me interessa mais nesse momento), como encarar as novas formas sociais de organização da vida, como levar a mensagem cristã num mundo que experimenta o vazio de um presentismo contínuo e da recusa de se saber insuficiente frente ao problema humano?

O concílio foi uma tentativa de resposta frente aos desafios que anunciavam uma "nova hora". Não esqueçamos que mesmo entre os historiadores existem aqueles que o enxergam como uma "virada epocal", um bom adjetivo para aqueles findos anos 1960, marcados por certo incremento na verborragia dos "novos tempos". Entre os "iludidos do concílio" ${ }^{4}$, - os fautores desejosos de colocar a Igreja vis a vis com a "nova hora" e que carregavam as perspectivas mais inovadoras - estavam aqueles que - com João XXIII sentiam só a brisa primaveril que entrava pelas janelas da Igreja a fim de renová-la.

Por outro lado, surgiram também aqueles que, desde a preparação até o final dos debates conciliares, lutavam por se manterem puros e imaculados frente à emergência de categorias modernas na Igreja através da teologia ${ }^{5}$, e que, de inúmeras maneiras visavam formar um dique de contenção à maré modernista que tomava a frente da arrebentação para, por fim, talvez inva-

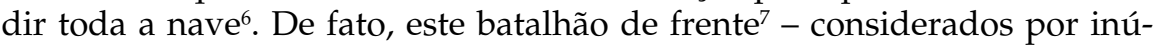

\footnotetext{
${ }^{4}$ A. MELLONI, "O que foi o Vaticano II? Breve guia para os juízos sobre o concílio", Concilium (2005/n.312) 34-59.

${ }^{5}$ Garrigou-Lagrange, Teilhard de Chardin, Romano Guardini, Karl Rahner, MarieDominique Chenu, Yves Congar, Henri de Lubac, Hans Urs Von Balthasar, Edward Schillebeeckx e Bernard Lonergan podem ser citados como os grandes representantes dessa nova teologia. Cf. B. MONDIN, Os grandes teólogos do século XX, v. 1, São Paulo: Paulinas, 1979; R. GIBELLINI, La teologia del XX secolo, Roma: Queriniana, 2007.

${ }^{6}$ Segundo Maritain, "[t]endo em vista a febre neo-modernista bastante contagiosa, pelo menos nos círculos denominados 'intelectuais', comparado com a qual o modernismo de Pio X não é senão uma modesta febre dos fenos, e que encontra expressão, sobretudo nos pensadores mais avançados entre os nossos irmãos protestantes, mas que também é activa nos pensadores católicos igualmente avançados, esta segunda descrição dá-nos o quadro de uma espécie de 'apostasia imanente' (compreendo que ela está decidida a ficar cristã a todo o custo), em preparação já de há muitos anos, levantadas aqui e acolá por ocasião do Concílio, aceleram a manifestação mentirosamente imputada, às vezes, ao 'espírito do Concílio', isto é, 'ao espírito de João XXIII'. Sabemos muito bem a quem se deve atribuir a paternidade de tais mentiras (e tanto melhor se assim o homem fica um pouco desonrado) [...]". J. MARITAIN, $O$ camponês do Garona, Lisboa: União Gráfica, 1967, p. 15.

7 Denomino este grupo de baluartes da tradição. Grosso modo, poderíamos nomear alguns de seus membros durante o concílio: os brasileiros Sigaud, Mayer; os italianos Carli, Ottaviani, Ruffini e Siri; os francófonos Lefebvre e Prou, entre outros.
} 
meros epítetos, como "conservadores", "tradicionalistas" ou "neointegristas" - fez de tudo para travar o processo de aproximação da Igreja aos valores modernos, exigindo condenações, anátemas e exclusões 9 . Eram os representantes da dita intransigência católica ${ }^{10}$.

O leitor deve estar se perguntando porque entrei nesta seara, já que meu objetivo geral neste artigo é revisitar uma bibliografia fundamental referente ao Vaticano II. A justificativa vem do fato da importância de se chamar a atenção para um fator hermenêutico ao se tratar do tema: a história efeitual. Não podemos deixar de notar - o que esbarraria em certa ingenuidade intelectual - que nesses quase cinquenta anos de recepção do concílio sofremos todo o tipo de influências interpretativas sobre o evento. Como dito acima, muito se falou sobre ele, e, como sabemos, as palavras, depois de soltas pelo ar, tornam-se livres de serem entendidas, pensadas, reelaboradas e mesmo resignificadas das formas mais variadas.

Ao se falar hoje do evento conciliar, não podemos ceder a uma "ilusão objetivista", que, ao estudarmos os documentos, as atas e todo o material que circulava entre os Padres do Vaticano II, chegaríamos à verdade nua e crua do concílio. Que mesmo ao estudar profundamente o desenrolar dos

\footnotetext{
${ }^{8} \mathrm{Um}$ dos melhores textos em português que tratam destas categorias - e as confusões em torno do conceito fundamentalismo - é o de A.F. PIERUCCI, "Fundamentalismo e integrismo: os nomes e a coisa", Revista USP (1992/n.13) 144-156.

${ }^{9} \mathrm{Na}$ consulta feita aos bispos de todo o mundo sobre os pontos que deveriam ser discutidos no concílio, Geraldo de Proença Sigaud, arcebispo de Diamantina, afirmava na sua carta-resposta: "tem havido bastantes pronunciamentos, embora não suficientes. Até hoje o maritainismo não foi condenado, embora os erros e o espírito do maritainismo sejam muito espalhados, e estejam causando grande mal nos países da América Latina [...]. É preciso organizar em âmbito mundial a luta contra as doutrinas e os fautores da doutrina, principalmente dentro do Clero e das Ordens Religiosas [...]" (J.O. BEOZZO [org.], Fundo Vaticano II das Bibliotecas dos Redentoristas de São Paulo, 168.1/002).

10 Todo nome carrega um peso semântico. Não podemos deixar de notar que ao falarmos "intransigente" ou "integrista" já situamos política e simbolicamente estes indivíduos que desejaram negar a possibilidade de qualquer encontro com a modernidade. Seriam indivíduos de "segunda ordem" dentro de um panorama religioso específico. Aqui gostaria de me aprofundar um pouco mais, já que esta questão de como abordar o fenômeno, como nomeá-lo, é de fundamental importância para darmos passos mais compreensivos sobre ele. Contudo, se o fizesse, fugiria do objetivo do artigo. É importante nos atermos às perguntas sobre os fundamentos de uma metodologia para analisarmos grupos religiosos que se imbuem de um tom que nega qualquer possibilidade de transigência com os valores modernos como o subjetivismo, o historicismo e a tolerância. De fato, estes grupos possuem uma gramática específica que pode ser compreendida a partir de sua própria constituição. Parece que um olhar epistemológico que preze uma perspectiva fenomenológica ou mesmo etnometodológica poderia ser um caminho. Cf. A. TERRIN, O sagrado off limits, Petrópolis: Vozes, 1998; K.P. GOSS, "As correntes interacionistas e as suas repercussões nas teorias de Anthony Giddens e Bruno Latour", Ciências Sociais UNISINOS 42 (2006/n.3) 153162. <http://redalyc.uaemex.mx/redalyc/pdf/938/93842301.pdf>
} 
debates, a preparação e reenvios dos documentos principais para serem refeitos pelas comissões destinadas à tarefa, sofremos as influências dos discursos produzidos até hoje sobre o evento. Como diz Gadamer, "entender é, essencialmente, um processo de história efeitual"11. Dessa maneira, devemos estar conscientes dos efeitos que reverberam nas mentes dos estudiosos a cada nova análise, a cada novo artigo e livro sobre o concílio do século XX.

Quer-se chamar a atenção para o fato de que "quando procuramos compreender um fenômeno histórico a partir da distância histórica que determina nossa situação hermenêutica como um todo, encontramo-nos sempre sob os efeitos dessa história efeitual"12. Assim, perguntarmos de onde produzimos nossas análises e sob quais condições noéticas as validamos. É necessário que reconheçamos os efeitos que essa história opera sob nossa compreensão a fim de tomarmos certa consciência de que "ser histórico quer dizer não se esgotar nunca no saber-se"13. Além disso, poderíamos sugerir - junto de Paul Ricoeur - a partir dessas primeiras reflexões sobre a história efeitual - que "compreender é compreender-se diante do texto", fazendo a compreensão "tornar-se, então, tanto desapropriação quanto apropriação"114. Dessa forma, nossa posição no mundo e nosso lugar de receptor de uma história contada por outros, de sentidos e interpretações construídas pelos agentes do conhecimento institucionalizado ou não, precisa ser o tempo inteiro medida e compreendida como locus de influências múltiplas e variadas.

Assim sendo, a perspectiva que assumo frente aos "reais" significados do Concílio Vaticano II, seja em seus textos, seja em seu dito "espírito" - termo utilizado corriqueiramente por estes ou aqueles grupos a fim de se "apossarem" do concílio, ou mesmo o repelir, e que carrega cargas semânticas diferenciadas para cada um deles - baseia-se em uma compreensão epistemológica que sempre retoma e reenvia o objeto de estudo, isto é, o evento conciliar, à reflexão de nossa própria condição de agentes noéticos. Se não fazemos esse exercício de entendimento da nossa posição de agentes receptores de um texto podemos cair corriqueiramente em ilusões fáceis. De fato, falta-nos, muitas vezes, um entendimento dessa dimensão da compreensão, que no confronto de ideias pode esbarrar numa tendência de "autoprivilégio epistêmico" ou "assimetria epistêmica", "isto é, nossa inclinação a pensar que acreditamos nas coisas verdadeiras e razoáveis, ao passo que outras pessoas acreditam nas coisas tolas e revoltantes em que acreditam porque há algo errado com elas" ${ }^{15}$. Eis o nó com que nos encon-

\footnotetext{
${ }^{11}$ H.G. GADAMER, Verdade e método. Traços fundamentais de uma hermenêutica filosófica, Petrópolis: Vozes, 1999, p. 448.

${ }^{12}$ Ibid., p. 449.

${ }^{13}$ Ibid., p. 451.

${ }^{14}$ P. RICOEUR, Interpretação e ideologia, Rio de Janeiro: Francisco Alves, 1997, pp. 58-59.

${ }^{15}$ B.H. SMITH, Crença e resistência, São Paulo: UNESP, 2002, p. 17.
} 
tramos ao tentar falar, por exemplo, de grupos de cuja gramática específica não comungamos ${ }^{16}$.

Ao fazer este adendo, alguns podem ter pensado que trataria, especialmente, das questões interpretativas específicas do Concílio Vaticano II, como as regras hermenêuticas do cardeal Walter Kasper ou a discussão que Francis Sullivan faz em um de seus importantes livros ou mesmo as aporias em torno das formas de avaliar os documentos emanados da assembleia ${ }^{17}$. Concluída esta etapa de apresentação teórico-hermenêutica - o que merece ser desenvolvido mais acuradamente em próximos estudos -, passamos à apresentação das principais obras para o estudo do Concílio Vaticano II e alguns comentários.

\section{Bibliografia fundamental para o estudo da história do Concílio Vaticano II}

O número de obras e artigos referentes ao Vaticano II é imenso. Na Itália, França, EUA e Brasil encontramos uma infinidade de estudos, de todo tipo, sobre os textos, os impactos e o pós-concílio, interpretações gerais e aquelas que prezam pelo local, trazendo à tona os principais personagens do evento. Dessa forma, tratarei neste texto apenas das obras e não dos artigos, vista a sua infinidade.

Num primeiro momento me vêm à mente as quatro obras principais que utilizei no desenrolar de minha tese: História do Concílio Vaticano $I I^{18}, \mathrm{O}$

\footnotetext{
${ }^{16}$ Entendo gramática como "a organização articulada de uma percepção, uma reflexão ou uma experiência; como a estrutura nervosa da consciência quando se comunica com si mesma e com os outros”. G. STEINER, Gramáticas da criação, São Paulo: Globo, 2003, p. 14.

${ }^{17}$ Cf. W. KASPER, Teologia e Chiesa, Brescia: Queriniana, 1989; F. SULLIVAN, Il magistero nella Chiesa Cattolica, Assisi: Cittadella, 1993; F. SULLIVAN, Capire e interpretare il magistero, Bologna: Dehoniane, 1997. Sobre a questão da avaliação dos documentos do Vaticano II é interessante citar que existem três formas de fazê-la: 1. Minimalista - G. Hering, H. Lattanzi, A. Gutierrez - o caráter pastoral do Vaticano II privou sua doutrina de força vinculante; 2. Maximalista - Umberto Betti - eleva a maior parte dos documentos conciliares praticamente à categoria de dogma; "Os capítulos das constituições têm o mesmo valor dos capítulos doutrinais dos outros concílios ecumênicos, em particular, os concílio de Trento e Vaticano I"; 3. Moderados - Y. Congar e J. Ratzinger - mesmo o Vaticano II não tendo expresso nenhuma definição dogmática, ele deve ser recebido pelos católicos como expressão do supremo magistério da Igreja, e isso implica uma certa obrigação de aceitá-lo. Cf. um texto de Y. CONGAR, "À guisa de conclusão", in F. VIER (org.), A Igreja do Vaticano II, Petrópolis: Vozes, 1965.

${ }_{18}$ G. ALBERIGO (org.), História do Concílio Vaticano II, vol. I, Petrópolis: Vozes, 1996; ID. (org.), História do Concílio Vaticano II, vol. II, Petrópolis: Vozes, 2000; ID. (org.), Storia del Concilio Vaticano II: il concilio adulto, vol. III, Bologna: Il Mulino,
} 
Reno se lança no Tibre: o concílio desconhecido ${ }^{19}$, O Concílio Vaticano II (documentário pré-conciliar e sessões) ${ }^{20}$, A Igreja do Brasil no Concílio Vaticano II ${ }^{21}$.

A primeira delas, a central História do Concílio Vaticano II organizada por Giuseppe Alberigo, o seminal historiador de Bologna morto em 2007, é o ainda único estudo historiográfico de peso sobre o evento conciliar. São cinco grossos volumes que tratam - a partir de análises de um grupo de historiadores e estudiosos de vários países - do concílio desde o seu primeiro momento, com a intuição de João XXIII, até as comissões pós-conciliares instituídas por Paulo VI no final de 1965 e início de 1966. Fartamente documentada, a História do Concílio traz o dia a dia dos debates conciliares, das comissões, da presidência e de todos os organismos envolvidos na empreitada, além, é claro, dos momentos mais "quentes" das discussões, com seus dilemas e polêmicas. De fato, é impossível tratar do concílio sem passar por estes volumes. Contudo, duas questões devem ser chamadas à atenção: no Brasil a Editora Vozes publicou somente os dois primeiros volumes. Sem interesse de publicar o restante da coleção, ela pode ser encontrada, por exemplo, em italiano pela editora II Mulino e em francês por Éditions du Cerf. O outro ponto que o estudioso que busque estudar o concílio deve ter em mente ao ler o texto de Alberigo e seus colegas é que, em muitos pontos da obra, o linguajar utilizado remete, indubitavelmente, ao orbe progressista do concílio e do pós-concílio. A visão de João XXIII, aberto às demandas modernas, contra a Cúria Romana, fechada em sua "intransigência antimoderna", - que por sinal foi rebatida por um importante intelectual italiano ${ }^{22}$ - a tomada de posição clara ao afirmar como

1998; ID. (org.), Storia del Concilio Vaticano II: la chiesa come communione, vol. IV, Bologna: Il Mulino, 1999; ID. (org.), Storia del Concilio Vaticano II: concilio di transizione, vol. V, Bologna: Il Mulino, 2001. Uma recensão sobre a obra pode ser lida em: P. VALLIN, "Vatican II, l'événement des historiens", Recherches de Science Religieuse 93 (2005/n.2) 215-245.

${ }_{19}$ R.M. WILTGEN, O Reno se lança no Tibre: o concílio desconhecido, Niterói: Permanência, 2007. Lançado originalmente em inglês e também traduzido para o francês: R.M. WILTGEN, The Rhine flows into the Tiber: a history of Vatican II, Rockford: TAN, 1985; R.M. WILTGEN, Le Rhien se jette dans le Tibre, Paris: Du Cèdre, 1976.

20 B. KLOPPENBURG, Concílio Vaticano II: documentário preconciliar, vol. I, Petrópolis: Vozes, 1962; ID., Concílio Vaticano II: primeira sessão (set-dez. 1962), vol. II, Petrópolis: Vozes, 1962; ID., Concílio Vaticano II: segunda sessão (set-dez. 1963), vol. III, Petrópolis: Vozes, 1963; ID., Concílio Vaticano II: terceira sessão (set-dez. 1964), vol. IV, Petrópolis: Vozes, 1963; ID., Concílio Vaticano II: quarta sessão (setdez. 1965), vol. V, Petrópolis: Vozes, 1965.

${ }_{21}^{2}$ J.O. BEOZZO, A Igreja do Brasil no Concílio Vaticano II (1959-1965), São Paulo: Paulinas, 2005.

${ }_{22}^{2}$ G. CAPRILE, "Profilo de Giovanni XXIII", La Civiltà Cattolica 130 (1979/n.3101) 392-398; ID., “Ancora su Giovanni XXIII", La Civiltà Cattolica 131 (1980/n.3115) 4954. 
"Semana Negra" (nome dado pelos bispos holandeses) aquela semana de 1964 em que Paulo VI reenvia o texto sobre a liberdade religiosa para ser discutido em 1965, as suas emendas sobre o esquema sobre o ecumenismo, a sua declaração de Maria "Mãe da Igreja" e a Nota Praevia ao texto da Constituição Lumen Gentium, são fatos que deixam claro o lugar de onde reverbera a sua história do concílio. Além disso, é necessário frisar que Alberigo era um amigo próximo do Cardeal Lercaro, um dos nomes fortes do grupo mais progressista do concílio, além de Bologna em si ser considerada uma cidade "de esquerda". Isso não tira o mérito do trabalho minucioso e central da "Escola de Bologna", mas o estudioso atento deve se precaver de tomar esta história como um todo sem uma crítica mais acurada, caindo no risco de repetir um discurso sem análise anterior de seus pressupostos, inclusive, e principalmente, temporais ${ }^{23}$.

A segunda obra apontada - O Reno se lança no Tibre: o concílio desconhecido-, do verbita Ralph Wiltgen, ajuda-nos a olhar o concílio pelos olhos daquele que foi o veículo pelo qual o Coetus Internationalis Patrum ${ }^{24}$ trazia a público seus posicionamentos durante o concílio. Wiltgen montou durante todo o concílio o Divine Word News Service, uma agência de notícias que fazia o trabalho de acompanhar e recolher informações nos debates, reverberando-as através de um informativo distribuído aos Padres. Wiltgen dá uma versão do concílio partindo do ponto de vista dos Padres do Coetus, e tal fato deve-nos remeter a certos cuidados. Geralmente, alguns movimentos tradicionalistas - como a Fraternidade Sacerdotal São Pio X - querem extrair dele uma história de conspiração maquiavélica, bem na esteira da obra da década de 1970 de Marcel Lefebvre Do liberalismo à apostasia: a tragédia conciliar ${ }^{25}$. Não se pode negar que os bispos do norte (Áustria, Holanda, Bélgica, Suíça, Alemanha) tinham afinidades teológicas que os levaram a tomar posicionamentos conjuntos na assembleia, além de alguns movimentos na própria estrutura administrativa - como o próprio Wiltgen demonstra em seu livro, tanto como os colaboradores de Alberigo. As informações dadas por Wiltgen são ricas, mesmo que sem referências claras no decorrer do texto. Além de podermos notar um outro olhar frente ao desenrolar conciliar, os informativos traziam as palavras da minoria conciliar, algo importante para quem deseja se aprofundar sobre objeto ainda pouco explorado ${ }^{26}$.

${ }^{23}$ R.C. CALDEIRA, "Reflexões acerca da continuidade e descontinuidade no Vaticano II: possibilidades de análise", Revista de Cultura Teológica 3 (2008) 1-13.

${ }^{24}$ R.C. CALDEIRA, Os baluartes da tradição: a antimodernidade católica brasileira no Concílio Vaticano II, Tese de doutorado, Programa de Pós-Graduação em Ciência da Religião da Universidade Federal de Juiz de Fora, 2009.

${ }^{25}$ M. LEFEBVRE, Do liberalismo à apostasia: a tragédia conciliar, Rio de Janeiro: Permanência, 1991.

${ }^{26} \mathrm{Na}$ Congregação do Verbo Divino em Roma encontra-se toda a coleção dos informativos do Divine Word News Service. 
O terceiro conjunto de textos - cinco volumes -, denominado geralmente pelos historiadores como Crônicas do concílio, é o organizado por Boaventura Kloppenburg, falecido em 2009. O franciscano acompanhou de perto o dia a dia dos debates conciliares anotando as intervenções orais que foram proferidas durante o Vaticano II, trazendo detalhes de sua preparação, de seu desenrolar, os discursos de João XXIII e Paulo VI e os documentos aprovados. Kloppenburg traz até mesmo, em alguns casos, a tradução direta das intervenções feitas em latim ${ }^{27}$. Acompanhando cada congregação geral, ou seja, aqueles dias em que os Padres reuniam-se em assembleia para discutirem os textos, sugerindo emendas e votando placet ou non placet, Kloppenburg oferece em língua portuguesa cada intervenção, além de análises minuciosas do que estava acontecendo ${ }^{28}$. Indispensável para quem deseja fazer a história do concílio ou se aprofundar em seus debates.

Obra importante e interessante por várias informações trazidas - como, por exemplo, alguns dos "paradoxos de João XXIII" - é a do alemão (no caso traduzido para o italiano) Otto Hermann Pesch, Il Concilio Vaticano II: preistoria, svolgimento, risultati, storia post-conciliare ${ }^{29}$. Neste livro, como esclarece o título, Pesch faz o caminho desde a pré-história do concílio até à pergunta "un terzo concilio Vaticano?". As análises do teólogo são fundamentais e ricas de possibilidades. Pesch trata de todos os momentos mais marcantes do concílio. Contudo, o que chama a atenção é a seção em que trata de algumas regras para a interpretação dos textos do magistério, especialmente do Vaticano II. Ao tratar das dificuldades interpretativas posteriores ao concílio, Pesch afirma que elas são frutos de um "compromisso do pluralismo contraditório" ${ }^{\prime 30}$, que perpassou toda a assembleia, especialmente sob influxo de Paulo VI e sua política de aprovação com maioria dos textos em discussão. Outro ponto interessante desta seção é o que trata do tão proferido "espírito do concílio". Alguns falam em "espírito do concílio" sem remeter ao significado que desejam dar a tal termo. Pesch nos ajuda ao afirmar que tal "espírito" consiste na vontade da maioria dos Padres conciliares, e não numa nebulosa carta de intenções daqueles que desejavam que o concílio tomasse posição frente a esta ou àquela reflexão.

Outra obra seminal para o estudo do concílio, tendo em foco o episcopado brasileiro e as relações estabelecidas no desenrolar do evento é o livro $A$ Igreja do Brasil no Concílio Vaticano II (1959-1965), do historiador José

\footnotetext{
${ }^{27}$ Pude perceber isso ao ler as intervenções de Sigaud e Mayer nas Acta Synodalia, onde se encontram todas as intervenções dos Padres conciliares, quer escritas quer orais, e comparei com algumas transcritas literalmente por Kloppenburg.

${ }^{28}$ Em outras línguas também podemos encontrar crônicas semelhantes: G. CAPRILE, Il Concilio Vaticano II, 5 volumi, Roma: Civiltà Cattolica, 1966-1968; H. FESQUET, Le journal du Concile, St. Martin: Folcalquier, 1966.

${ }_{29}^{29}$ O.H. PESCH, Il Concilio Vaticano II: preistoria, svolgimento, risultati, storia postconciliare, Roma: Queriniana, 2005.

${ }^{30}$ Ibid., p. 148.
} 
Oscar Beozzo, colaborador direto de Giuseppe Alberigo no Brasil ${ }^{31}$. Fruto de uma tese de doutorado defendida em 2001 em História na Universidade de São Paulo, este estudo é fundamental por construir uma prosopografia do episcopado brasileiro no concílio. Beozzo apresenta os dados de todos os Padres brasileiros participantes da grande reunião. Divide seu estudo em três partes: na primeira aborda o anúncio e a preparação do concílio, refletindo sobre a recepção da notícia entre os bispos brasileiros a partir das respostas à "consulta Tardini"; na segunda trata do concílio como fenômeno político, a importância da Domus Mariae e do colégio Pio Brasileiro na aproximação dos Padres, as redes de relações do concílio, as conferências apresentadas na Domus Mariae, alguns elementos para interpretações da participação do episcopado brasileiro, o plano de emergência e o plano de pastoral de conjunto; na terceira parte traz, então, a prosopografia do episcopado brasileiro, juntamente a um interessante caderno iconográfico. Este trabalho de Beozzo é fundamental para se aprender os passos do episcopado brasileiro, da preparação do concílio à conclusão, já que traz o ineditismo da temática em solo brasileiro, além de trazer à tona uma gama de bibliografias e fontes também inéditas por aqui.

Podemos apontar igualmente alguns diários pessoais do concílio que também ajudam a clarear as discussões e a entender o que estava em jogo nos debates. Nos trabalhos historiográficos sobre o evento conciliar são profundamente utilizados para aparar as arestas de fontes diversas. Muitos diários e correspondências que têm como referência o Vaticano II foram publicados nos últimos anos, inclusive no Brasil ${ }^{32}$. O que mais utilizei em meu trabalho foi o diário do teólogo Yves Congar, na sua tradução italiana ${ }^{33}$. Em dois volumes, Congar passa quase que diariamente comentando os rumos e dilemas do concílio, transparecendo os principais atores das comissões e as relações entre alguns Padres e teólogos do concílio.

Os trabalhos de dois renomados historiadores da Igreja moderna e contemporânea também podem colaborar na busca de estabelecer uma temporalidade específica para se compreender o Vaticano II: Danielle Menozzi com seu Giovanni Paolo II: una transizione incompiuta? ${ }^{34}$ e Émile Poulat com Une

$31 \mathrm{Na}$ esteira desta obra, podemos citar também como um importante texto sobre o episcopado brasileiro e latino-americano, também organizado pelo historiador: J.O. BEOZZO (org.), A Igreja Latino-Americana às vésperas do Concílio: história do Concílio Ecumênico Vaticano II, São Paulo: Paulinas, 1993.

${ }^{32}$ Podemos citar como exemplo a caixa que traz inúmeras cartas de D. Hélder Câmara da época do concílio. Cf. R. FARIA et alii, Dom Hélder Câmara - Box, Recife: CEPE, 2009.

33 Y. CONGAR, Diario del Concilio, 2 volumi, Milano: San Paolo, 2005.

34 Uma recensão do livro (D. MENOZZI, Giovanni Paolo II: una transizione incompiuta?, Brescia: Morcelliana, 2006) encontra-se em Horizonte Teológico 6 (2007/ n.12) 154-156. Um texto importante de Menozzi também se encontra em um livro publicado em homenagem a Émile Poulat por ocasião de um colóquio realizado na 
Église ébranlée ${ }^{35}$. Ambos constroem uma história da Igreja católica no século XX, com diferenças cronológicas, mas com análises que se aproximam em alguns pontos. Menozzi parece, nesse livro, romper de certa forma com a perspectiva da hermenêutica de ruptura seguida pelos historiadores de Bologna, ao buscar - na primeira parte da obra - compreender como a Igreja seguiu pelo início do século XX até o concílio, visando demonstrar que nos diferentes papados é possível encontrar posicionamentos de "abertura" e de "fechamento", dependendo da chave interpretativa utilizada. Parece que Menozzi visa romper com aquela ideia corriqueiramente anunciada em textos acadêmicos de que os papados, de Pio IX a Pio XII, foram estritamente "antimodernos". Contra a ideia preponderante que vem de Bologna - aquela que Alberigo defende ao afirmar que a Igreja passa "do bastão à misericórdia"36 quando Ângelo Roncalli chega ao papado - o historiador da Scuola Normale Superiore di Pisa afirma que a Igreja do século XX leva a cabo uma "modernização antimodernista", não conseguindo "decidir se mostra sua face de mãe misericordiosa ou de sombria madrasta" ${ }^{\prime 37}$.

Poulat, por sua vez, já traz no título de seu livro as pistas de sua análise que trata da Igreja de Pio XII a João Paulo II: mudança, conflito e continuidade. Ao comentar as palavras de Yves Congar sobre o concílio, um dos maiores historiadores do catolicismo contemporâneo faz uma afirmação não muito grata aos círculos que pautam suas ações eclesiais tendo como pano de fundo a hermenêutica descontínua. Segundo ele, com o Vaticano II presenciamos o "fim de uma tradição" com a "persistência de um modelo". Este modelo, que persistiu mesmo depois do concílio, baseia-se em três pilares: negação da ideia de autonomia que prescinda de Deus; incentivo à modernização da atuação dos católicos no meio social, contanto que não coloque em risco a busca da "cidade cristã"; negação e condenação do modernismo como assimilação sub-reptícia das autonomias política, social e cultural da modernidade ${ }^{38}$.

Um conjunto de obras, todas vindas de Bologna, também é de importância crucial para o debate, já que trazem algumas reflexões sobre discussões

\footnotetext{
Sorbonne em 1999 sobre o catolicismo como objeto de estudo. Cf. D. MENOZZI, "L'Église et la modernité: une relation compliquée", in V. ZUBER (org.), Un objet de science, le catholicisme. Réflexions autour de l'œuvre d'Émile Poulat, Lonrai: Bayard, 2001

${ }_{35}$ E. POULAT, Une Église ébranlée: changement, conflit et continuité de Pio XII à Jean Paul II, Paris: Casterman, 1980.

${ }_{36} \mathrm{O}$ artigo de Alberigo "Do bastão à misericórdia. O magistério no catolicismo contemporâneo (1830-1980)" encontra-se em G. ALBERIGO, A Igreja na História, São Paulo: Paulinas, 1999.

${ }^{37}$ D. MENOZZI, Giovanni Paolo II: una transizione incompiuta?, Brescia: Morcelliana, 2006, p. 11.

${ }^{38}$ E. POULAT, Une Église ébranlée: changement, conflit et continuité de Pio XII à Jean Paul II, Paris: Casterman, 1980, p. 290.
} 
específicas na assembleia ou balanços avaliativos sobre os rumos da Igreja no pós-concílio. São eles: Volti di fine concilio: studi di storia e teologia sulla conclusione del Vaticano II ${ }^{39}$; Una difficile transizione: il cattolicesimo tra unionismo ed ecumenismo ${ }^{40}$; Il vescovo e il concilio: modello episcopale e aggiornamento al Vaticano II ${ }^{41}$; La fatica della libertà: l'elaborazione della dichiarazione 'Dignitatis humanae' sulla libertà religiosa del Vaticano II ${ }^{42}$; Il Vaticano II e la Chiesa ${ }^{43}$.

Doré e Melloni em Volti di fine concilio congregam vários textos de especialistas sobre os momentos posteriores da conclusão do Vaticano II. Quatro capítulos específicos chamam a atenção: Le Concile Vatican II vu par les observateurs des autres traditions chrétiennes (André Birmelé), que traz um retrato de como os observadores das outras tradições cristãs avaliaram a empreitada do concílio; Medellín. Inspiration et racines (Oscar Beozzo), que visa apontar para as relações entre o Vaticano II e a Conferência de Medellín, como forma de recepção do concílio; Le valutazioni sulla Gaudium et spes: Chenu, Dossetti, Ratzinger (Joseph A. Komonchak) traz um estudo das posições dos Padres referidos ao esquema XIII, que deu origem à Gaudium et spes, desde seus primeiros esboços até a votação final do documento; Delusioni alla fine del concilio. Qualche atteggiamento nell'ambiente cattolico francese (Giuseppe Ruggieri) vale o livro. Nesse texto, Ruggieri traz uma grande contribuição aos estudiosos do concílio e do pós-concílio ao apontar os posicionamentos cada vez mais desiludidos com os resultados da assembleia no âmbito eclesial francês. Jacques Maritain, Étienne Gilson, Henri de Lubac, Jean Daniélou são os nomes que Ruggieri aponta entre os "desiludidos do concílio".

Na obra Una difficile transizione: il cattolicesimo tra unionismo ed ecumenismo, Mauro Velati traz uma central contribuição para aqueles que desejam compreender a face ecumênica do concílio. Em treze capítulos, marcados pela riqueza de inúmeras fontes, Velati visou demonstrar a passagem da Igreja católica de uma visão negativa do movimento ecumênico a seu pleno reconhecimento.

Em Il vescovo e il concilio: modello episcopale e aggiornamento al Vaticano II, Massimo Faggioli visa compreender a dinâmica das discussões em torno

${ }^{39}$ J. DORÉ / A. MELLONI (org.), Volti di fine concilio: studi di storia e teologia sulla conclusione del Vaticano II, Bologna: Il Mulino, 2000.

${ }^{40} \mathrm{M}$. VELATI, Una difficile transizione: il cattolicesimo tra unionismo ed ecumenismo (1952-1964), Bologna: Il Mulino, 1996.

${ }^{41}$ M. FAGGIOLI, Il vescovo e il concilio: modello episcopale e aggiornamento al Vaticano II, Bologna: Il Mulino, 2005.

${ }^{42}$ S. SCATENA, La fatica della libertà: l'elaborazione della dichiarazione 'Dignitatis humanae' sulla libertà religiosa del Vaticano II, Bologna: Il Mulino, 2003.

${ }^{43}$ G. ALBERIGO / J.P. JOSSUA (org.), Il Vaticano II e la Chiesa, Brescia: Paideia, 1985. 
da posição do episcopado na hierarquia da Igreja. Dessa forma, oferece uma análise historiográfica muito rica e interessante na medida em que acompanha o desenrolar de todas as discussões referentes ao esquema que se concluirá na Constituição Dogmática Lumen Gentium. As discussões acerca da questão de como equilibrar o primado papal (Vaticano I) com o poder dos bispos levou a vários debates acalorados, além de uma grande movimentação dos grupos extra aulam a fim de alcançarem seus objetivos. Muito rico em fontes primárias, esta obra é fundamental para se entender a "construção" do esquema sobre a Igreja, com suas marcantes reviravoltas no decorrer dos debates.

Outra obra na linha da escrita por Faggioli é La fatica della libertà: l'elaborazione della dichiarazione 'Dignitatis humanae' sulla libertà religiosa del Vaticano II, de Silvia Scatena. A historiadora visa neste livro refazer o caminho das discussões acerca do esquema que dará luz à Declaração Dignitatis Humanae, sobre a liberdade religiosa. Tanto quanto às discussões sobre o episcopado, ou mais, os debates em torno do tema das relações da Igreja católica com o Estado e as outras tradições religiosas foram um ponto de celeuma constante no concílio. Scatena consegue percorrer toda a história da escrita do esquema, da sua gênese até sua aprovação em dezembro de 1965, trazendo os principais personagens e os principais momentos de sua elaboração.

Em Il Vaticano II e la Chiesa temos um claro exemplo da literatura surgida no pós-concílio e que visava pensá-lo a partir de algumas linhas interpretativas ${ }^{44}$. Este livro comemora os vinte anos da conclusão do concílio e traz textos importantes para refletir a sua fase de recepção. Destaca alguns de seus capítulos: La condizione cristiana dopo il Vaticano II (Giuseppe Alberigo), que deixa bem claro em que termos Alberigo e seus seguidores compreendem o concílio; La recezione dell'ecumenismo (René Girault), que visa responder "qual ecumenismo o concílio propunha à Igreja" e como se deram os diálogos depois da realização da assembleia; La Chiesa e i poveri dall'America Latina (Gustavo Gutiérrez), que pode ser considerado um texto chave para aqueles que visam compreender como a dita "Teologia da Libertação" entendeu o Vaticano II; La ricezione del dibattito sulla collegialità (Lukas Vischer) que buscou apreender como se deu a recepção do capítulo III da Lumen gentium e esclarecer as tensões ainda não resolvidas entre o colégio episcopal e o primado papal; e, por último, L'anticoncilio (19661984) (Danielle Menozzi), que tratou da maturação histórica das ideias anticonciliares que cresceram naqueles círculos em torno dos tradicionalistas, principalmente de Marcel Lefebvre, durante o desenrolar do Vaticano II.

Um último livro também muito interessante e importante para os estudiosos do concílio é aquele organizado por René Latourelle - Vaticano II: bilancio

\footnotetext{
${ }^{44}$ Um estudo na mesma linha, também com inúmeros colaboradores, pode ser encontrado em língua inglesa: D.G. SCHULTENOVER (org.), Vatican II: Did anything happen?, New York: Continuum, 2007.
} 
e prospettive venticinque anni dopo (1962-1987) ${ }^{45}$ - em vista dos 25 anos do início do concílio. Chamo a atenção para o texto seminal que se insere na obra de Giacomo Martina, Il contesto storico in cui è nata l'idea di un nuovo concilio ecumenico. Num longo estudo, Martina demonstra de forma clara e detalhada o contexto político, cultural e eclesial do nascimento da ideia do Vaticano II, apresentando as forças em jogo, as orientações teológicas e pastorais entre os anos 1940 e 1960 a partir das intervenções romanas.

\section{Considerações finais}

Nesses quase cinquenta anos de início do Concílio Vaticano II ainda estamos sob o signo de suas contendas em vista de sua recepção. Dessa forma, inúmeras interpretações de seus textos, e sua história efeitual, ainda estão por serem feitas. Paralelamente a elas, ou mesmo a partir delas, desenrolase a luta entre os vários atores para se apossarem dos significados do concílio, sejam grupos eclesiais que se encontram na base da estrutura eclesiástica, sejam aqueles que se congregam em seu topo, em torno da cúria e do papa e que visam dar uma leitura oficial de seus documentos. O texto que se conclui teve como objetivo apontar, assim, algumas considerações hermenêuticas sobre o tema e apresentar uma breve revisão bibliográfica sobre a historiografia do maior evento eclesial do século XX.

\section{Referências bibliográficas}

ALBERIGO, G. (org.), História do Concílio Vaticano II, vol. I, Petrópolis: Vozes, 1996. História do Concílio Vaticano II, vol. II, Petrópolis: Vozes, 2000. Mulino, 1998. Storia del Concilio Vaticano II: il concilio adulto, vol. III, Bologna: Il Storia del Concilio Vaticano II: la chiesa come communione, vol. IV, Bologna: Il Mulino, 1999. Mulino, 2001.

Storia del Concilio Vaticano II: concilio di transizione, vol. V, Bologna: Il A Igreja na História, São Paulo: Paulinas, 1989.

ALBERIGO, G. / JOSSUA, J.P. (org.), Il Vaticano II e la Chiesa, Brescia: Paideia, 1985. BEOZZO, J.O., A Igreja Latino-Americana às vésperas do Concílio: história do Concílio Ecumênico Vaticano II, São Paulo: Paulinas, 1993. 2005. A Igreja do Brasil no Concílio Vaticano II (1959-1965), São Paulo: Paulinas,

${ }^{45}$ R. LATOURELLE (org), Vaticano II: bilancio e prospettive venticinque anni dopo (1962-1987), Assisi: Cittadella, 1987. 
CALDEIRA, R.C., "Bases temporais para o estudo histórico da Igreja católica no século XX", Horizonte 5 (2008) 75-90.

"Reflexões acerca da continuidade e descontinuidade no Vaticano II: possibilidades de análise", Revista de Cultura Teológica 3 (2008) 1-13.

Os baluartes da tradição: a antimodernidade católica brasileira no Concílio Vaticano II, Tese de doutorado, Programa de Pós-Graduação em Ciência da Religião da Universidade Federal de Juiz de Fora, 2009.

CAPRILE, G., Il Concilio Vaticano II, 5 volumi, Roma: Civiltà Cattolica, 1966-1968. “Profilo de Giovanni XXIII", La Civiltà Cattolica 130 (1979/n.3101) 392-398.

“Ancora su Giovanni XXIII", La Civiltà Cattolica 131 (1980/n.3115) 49-54.

CONGAR, Y., “À guisa de conclusão”, in F. VIER (org.), A Igreja do Vaticano II, Petrópolis: Vozes, 1965, pp. 1285-1292.

Diario del Concilio, 2 volumi, Milano: San Paolo, 2005.

DORÉ, J. / MELLONI, A. (org.), Volti di fine concilio: studi di storia e teologia sulla conclusione del Vaticano II, Bologna: Il Mulino, 2000.

FAGGIOLI, M., Il vescovo e il concilio: modello episcopale e aggiornamento al Vaticano II, Bologna: Il Mulino, 2005.

FARIA, R. et alii, Dom Hélder Câmara - Box, Recife: CEPE, 2009.

FESQUET, H., Le journal du Concile, St. Martin: Folcalquier, 1966.

GADAMER, H.G., Verdade e método. Traços fundamentais de uma hermenêutica filosófica, Petrópolis: Vozes, 1999.

GIBELLINI, R., La teologia del XX secolo, Roma: Queriniana, 2007.

GOSS, K.P., "As correntes interacionistas e as suas repercussões nas teorias de Anthony Giddens e Bruno Latour", Ciências Sociais UNISINOS 42 (2006/n.3) 153162 <http://redalyc.uaemex.mx/redalyc/pdf/938/93842301.pdf>

KASPER, W., Teologia e Chiesa, Brescia: Queriniana, 1989.

KLOPPENBURG, B., Concílio Vaticano II: documentário preconciliar, vol. I, Petrópolis: Vozes, 1962.

Vozes, 1962.

Concílio Vaticano II: primeira sessão (set-dez. 1962), vol. II, Petrópolis: Vozes, 1963.

Concílio Vaticano II: segunda sessão (set-dez. 1963), vol. III, Petrópolis: Vozes, 1963.

Concílio Vaticano II: terceira sessão (set-dez. 1964), vol. IV, Petrópolis: Vozes, 1965.

Concílio Vaticano II: quarta sessão (set-dez. 1965), vol. V, Petrópolis:

LATOURELLE, R. (org), Vaticano II: bilancio e prospettive venticinque anni dopo (1962-1987), Assisi: Cittadella, 1987.

LEFEBVRE, M., Do liberalismo à apostasia: a tragédia conciliar, Rio de Janeiro: Permanência, 1991.

MARITAIN, J., O camponês do Garona, Lisboa: União Gráfica, 1967. 
MENOZZI, D., "L'Église et la modernité: une relation compliquée”, in V. ZUBER (org.), Un objet de science, le catholicisme. Réflexions autour de l'ouvre d'Émile Poulat, Lonrai: Bayard, 2001, pp. 124-133.

Giovanni Paolo II: una transizione incompiuta?, Brescia: Morcelliana, 2006.

MONDIN, B., Os grandes teólogos do século XX, v. 1, São Paulo: Paulinas, 1979.

PAREYSON, L., Verdade e interpretação, São Paulo: Martins Fontes, 2005.

PESCH, O.H., Il Concilio Vaticano II: preistoria, svolgimento, risultati, storia postconciliare, Roma: Queriniana, 2005.

PIERUCCI, A.F., "Fundamentalismo e integrismo: os nomes e a coisa", Revista USP (1992/n.13) 144-156.

POULAT, E., Une Église ébranlée: changement, conflit et continuité de Pio XII à Jean Paul II, Paris: Casterman, 1980.

RICOEUR, P., Interpretação e ideologia, Rio de Janeiro: Francisco Alves, 1997.

SCATENA, S., La fatica della libertà: l'elaborazione della dichiarazione 'Dignitatis humanae' sulla libertà religiosa del Vaticano II, Bologna: Il Mulino, 2003.

SCHULTENOVER, D.G. (org.), Vatican II: Did anything happen?, New York: Continuum, 2007.

SMITH, B.H., Crença e resistência, São Paulo: UNESP, 2002.

STEINER, G., Gramáticas da criação, São Paulo: Globo, 2003.

SULLIVAN, F., Capire e interpretare il magistero, Bologna: Dehoniane, 1997. Il magistero nella Chiesa Cattolica, Assisi: Cittadella, 1993.

TERRIN, A., O sagrado off limits, Petrópolis: Vozes, 1998.

VALLIN, P., "Vatican II, l'événement des historiens", Recherches de Science Religieuse 93 (2005/n.2) 30.

VELATI, M., Una difficile transizione: il cattolicesimo tra unionismo ed ecumenismo (1952-1964), Bologna: Il Mulino, 1996.

WILTGEN, R.M., Le Rhien se jette dans le Tibre, Paris: Du Cèdre, 1976.

2007.

O Reno se lança no Tibre: o concílio desconhecido, Niterói: Permanência,

The Rhine flows into the Tiber: a history of Vatican II, Rockford: TAN, 1985.

Rodrigo Coppe Caldeira, historiador e doutor em Ciências da Religião pelo Programa de Pós-graduação em Ciências da Religião da Universidade Federal de Juiz de Fora, MG, é Professor Adjunto III do Departamento de Ciências da Religião da PUCMinas. É autor de Os baluartes da tradição: o conservadorismo católico brasileiro no Concílio Vaticano II, Curitiba: Ed. CRV, 2011.

Endereço: PUC - Minas Av. Dom José Gaspar, 500 / Prédio 4 (Coração Eucarístico) 30535-610 Belo Horizonte - MG e-mail: rcoppe@pucminas.br 